\title{
PENERAPAN MEDIA SIMULASI PHET TERHADAP HASIL BELAJAR KONSEP DASAR IPA MAHASISWA TADRIS IPA IAIN PALU
}

\author{
Arda \\ Program Studi Tadris IPA, FTIK, Institut Agama Islam Negeri Palu \\ ardhaphys@gmail.com
}

\begin{abstract}
ABSTRAK
Penelitian ini merupakan penelitian pra eksperimen yang bertujuan untuk mengetahui hasil belajar mahasiswa pada materi gaya dan hukum Newton dengan menggunakan media simulasi PhET. Subjek penelitian adalah 18 mahasiswa Tadris IPA yang memprogramkan mata kuliah Konsep Dasar IPA. Hasil analisis deskriptif menunjukkan bahwa skor rata-rata hasil belajar mahasiswa sebelum belajar dengan media simulasi PhET adalah 12,67 dan setelah belajar dengan media simulasi PhET adalah 15,78. Berdasarkan hasil analisis data yang dilakukan dengan menggunakan persamaan normalisasi gain diperoleh gain sebesar 0,42. Hal tersebut menunjukkan adanya peningkatan hasil belajar mahasiswa Tadris IPA dalam kategori sedang.
\end{abstract}

Kata Kunci: simulasi PhET, hasil belajar, Konsep Dasar IPA

\begin{abstract}
This research is pre experimental research. It aims to find out the result of students learning on forces and Newton's laws by using PhET simulation media. Subject of this research were 18 students of Tadris IPA who programmed the Basic Concepts of Natural Sciences courses. Descriptive analysis results the mean score of the student learning outcomes before the application of PhET simulation media were 12.67 and after treatment through of PhET simulation media were 15.78. The gain based on the results of data analysis using the gain normalization were 0.42. It means that there is improvement on the students of Tadris IPA learning outcomes in medium category.
\end{abstract}

Keywords: PhET simulation, learning outcomes, Basic Concepts of Natural Sciences

\section{PENDAHULUAN}

Kemajuan Teknologi Informasi dan Komunikasi (TIK) telah mempengaruhi hampir setiap aspek kehidupan manusia saat ini. Salah satunya dalam bidang pendidikan berupa pengembangan media pembelajaran. Adanya pemanfaatan TIK, media pembelajaran saat ini tidak terpaku kepada media pembelajaran konvensional semata namun juga dapat memanfaatkan penggunaan perangkat teknologi seperti handphone, tablet PC dan laptop (Darmawan, 2016).
Peranan media sangat penting dalam memperlancar kegiatan belajar mengajar. Belajar merupakan proses komunikasi atau penyampaian pesan yang dilakukan melalui kegiatan tukar menukar pesan atau informasi oleh setiap dosen dan mahasiswa. Pesan atau informasi dapat berupa ide, pengetahuan, keahlian dan pengalaman. Pesan atau informasi tersebut dapat dipahami dan dimengerti oleh orang lain melalui proses komunikasi (Pulungan, 2017).

Konsep Dasar IPA membahas 3 materi pokok yaitu Fisika, Kimia dan Biologi. Mahasiswa Tadris IPA yang berasal dari latar 
belakang pendidikan menengah atas yang beragam masih kesulitan dalam memahami ketiga konsep tersebut. Oleh karena itu, diperlukan media yang tepat dalam rangka memberikan pembelajaran yang lebih menarik agar mereka mudah memahami dan menguasai konsep dari materi yang diajarkan.

Kegunaan media antara lain:

1. Materi yang disampaikan lebih jelas dan tidak hanya bersifat verbal.

2. Keterbatasan ruang, waktu, biaya, tenaga dan daya indera dapat diatasi.

3. Peserta didik memiliki rangsangan pengalaman dan persepsi yang sama dalam belajar.

4. Motivasi belajar peserta didik lebih meningkat karena dapat belajar secara mandiri sesuai bakat dan kemampuannya (Daryanto, 2013).

Banyak media yang dapat digunakan dalam kegiatan belajar mengajar IPA. Salah satunya dengan menggunakan laboratorium virtual (virtual laboratory). Penggunaan laboratorium virtual memiliki banyak kelebihan antara lain tidak memerlukan alat dan bahan kimia khusus sehingga praktikum dapat dilakukan kapan dan di mana saja, bahaya pencemaran oleh bahan kimia dapat diminimalkan karena tidak menghasilkan limbah. Selain itu, kegiatan praktikum yang tidak dapat diamati secara langsung menjadi mungkin melalui animasi pada laboratorium virtual (Setiadi \& Muflika, 2012).

Salah satu laboratorium virtual yang dapat digunakan adalah PhET (Physics Education Technology). PhET merupakan salah satu situs yang menyediakan simulasi pembelajaran secara gratis yang dikembangkan oleh Universitas Colorado. Media simulasi PhET memuat materi pembelajaran Fisika, Kimia dan Biologi. Simulasi dirancang secara interaktif untuk kegiatan pembelajaran baik di kelas maupun mandiri sehingga pembelajaran langsung dapat dilakukan oleh setiap pengguna (Saregar, 2016).

Berdasarkan latar belakang tersebut maka dilakukan penelitian yang bertujuan untuk mengetahui penerapan media simulasi PhET terhadap hasil belajar Konsep Dasar
IPA Mahasiswa Tadris IPA IAIN Palu. Gaya dan hukum Newton merupakan materi yang dibahas dalam penelitian ini karena sering terjadi miskonsepsi dalam materi tersebut. Salah satunya adalah konsep pasangan aksi reaksi. Miskonsepsi terjadi karena adanya pandangan tentang "prinsip dominasi" dalam aksi-reaksi. Berdasarkan prinsip tersebut, benda yang bermassa lebih besar dan bergerak lebih aktif akan lebih kuat serta memberikan gaya yang lebih besar daripada pasangan reaksinya. Selain itu, adanya kekeliruan dalam membedakan antara pasangan aksi reaksi yang saling berlawanan arah (Zahroh, dkk., 2017).

\section{METODE PENELITIAN}

Penelitian pra eksperimen (preexperimental) dengan desain penelitian OneGroup Pretest-Posttest Design (Sugiyono, 2013).

Keterangan:

$$
\mathrm{O}_{1} \quad \mathrm{X} \quad \mathrm{O}_{2}
$$

$\mathrm{X}=$ Perlakuan berupa penggunaan media simulasi PhET

$\mathrm{O}_{1}=$ Skor pretest (sebelum diberi perlakuan)

$\mathrm{O} 2=$ Skor posttest (setelah diberi perlakuan)

Data hasil belajar Konsep Dasar IPA dianalisis menggunakan statistik deskriptif. Hasil penelitian yang diperoleh terdiri dari data awal (pretest) dan data akhir (posttest). Analisis data dilakukan dengan menggunakan persamaan normalisasi gain yang dikembangkan oleh Hake. Adapun persamaan tersebut adalah:

$$
\langle\mathrm{g}\rangle=\frac{\left(\mathrm{S}_{\mathrm{f}}\right)-\left(\mathrm{S}_{\mathrm{i}}\right)}{100 \%-\left(\mathrm{S}_{\mathrm{i}}\right)}
$$

Keterangan:

$\mathrm{g}=$ Gain

$\mathrm{S}_{\mathrm{f}}=$ Skor rata-rata posttest $(\%)$

$\mathrm{S}_{\mathrm{i}}=$ Skor rata-rata pretest $(\%)$

Ada tiga kategori gain hasil perhitungan:

1. Low-g (rendah) jika $g<0,3$.

2. Medium-g (sedang) jika $0,3 \leq \mathrm{g}<0,7$.

3. High-g (tinggi) jika $g \geq 0,7$ (Hake, 1998). 


\section{HASIL DAN PEMBAHASAN}

Mahasiswa yang telah mempelajari materi gaya dan hukum Newton melalui perkuliahan secara daring diberikan tes awal. Setelah itu mahasiswa belajar secara mandiri dengan menggunakan media simulasi PhET seperti yang ditampilkan pada Gambar 1 dan Gambar 2. Posttest kemudian diberikan kepada mahasiswa tersebut untuk mengetahui adanya peningkatan hasil belajar mereka. Skor hasil belajar tersebut dapat dilihat pada Tabel 1 .

Tabel 1. Skor Hasil Belajar Pretest dan Posttest Mahasiswa

\begin{tabular}{lcc}
\hline Statistik & Pretest & Posttest \\
\hline Jumlah mahasiswa & 18 & 18 \\
Skor ideal & 20 & 20 \\
Skor tertinggi & 16 & 20 \\
Skor terendah & 8 & 12 \\
Skor rata-rata & 12,67 & 15,78 \\
Standar deviasi & 3,13 & 2,57 \\
Variansi & 9,78 & 6,62 \\
Koefisien variansi & $24,70 \%$ & $16,29 \%$ \\
\hline
\end{tabular}

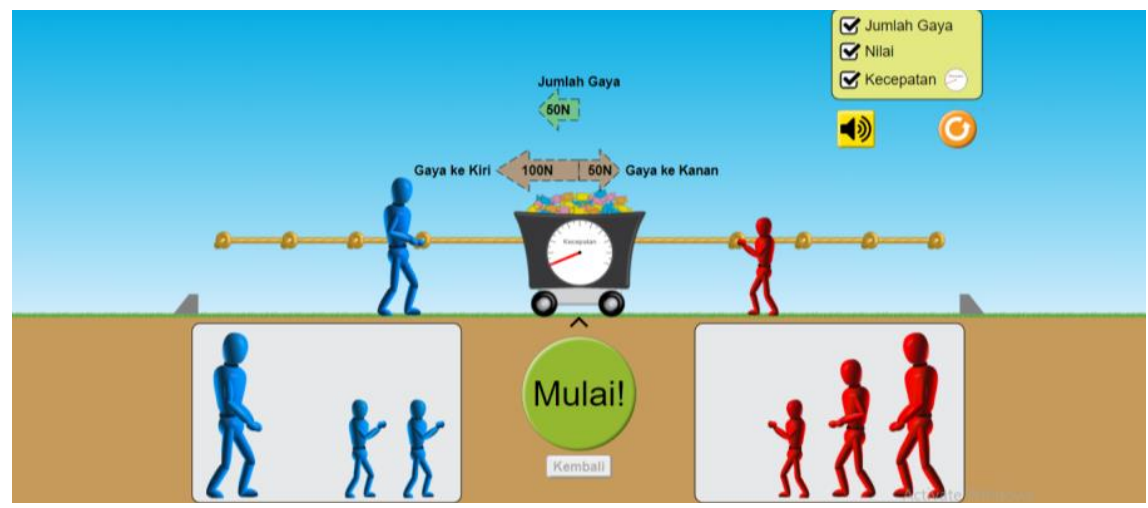

Gambar 1. Tampilan Simulasi PhET Penjumlahan Gaya

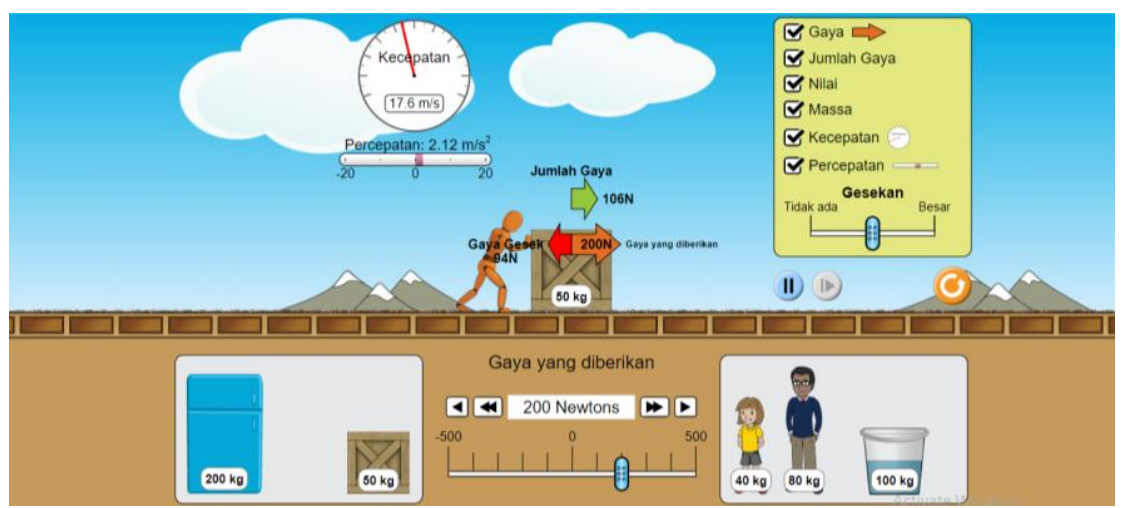

Gambar 2. Tampilan Simulasi PhET Percepatan

Berdasarkan Tabel 1 dapat ditarik kesimpulan bahwa rata-rata hasil belajar mahasiswa sebelum menggunakan media simulasi PhET adalah 12,67 dengan skor tertinggi 16 dan terendah 8 . Standar deviasi yang diperoleh adalah 3,13 dengan variansi 9,78 dan koefisien variansi $24,70 \%$. Sedangkan rata-rata hasil belajar mahasiswa setelah menggunakan media simulasi PhET adalah 15,78 dengan skor tertinggi 20 dan terendah 12. Standar deviasi yang diperoleh adalah 2,57 dengan variansi 6,62 dan koefisien variansi $16,29 \%$.

Adapun hubungan antara skor hasil pretest dan posttest mahasiswa dengan frekuensi dapat dilihat pada Gambar 3 dan Gambar 4. Sedangkan perbandingan skor 
rata-rata hasil pretest dan posttest dapat dilihat pada Gambar 5.

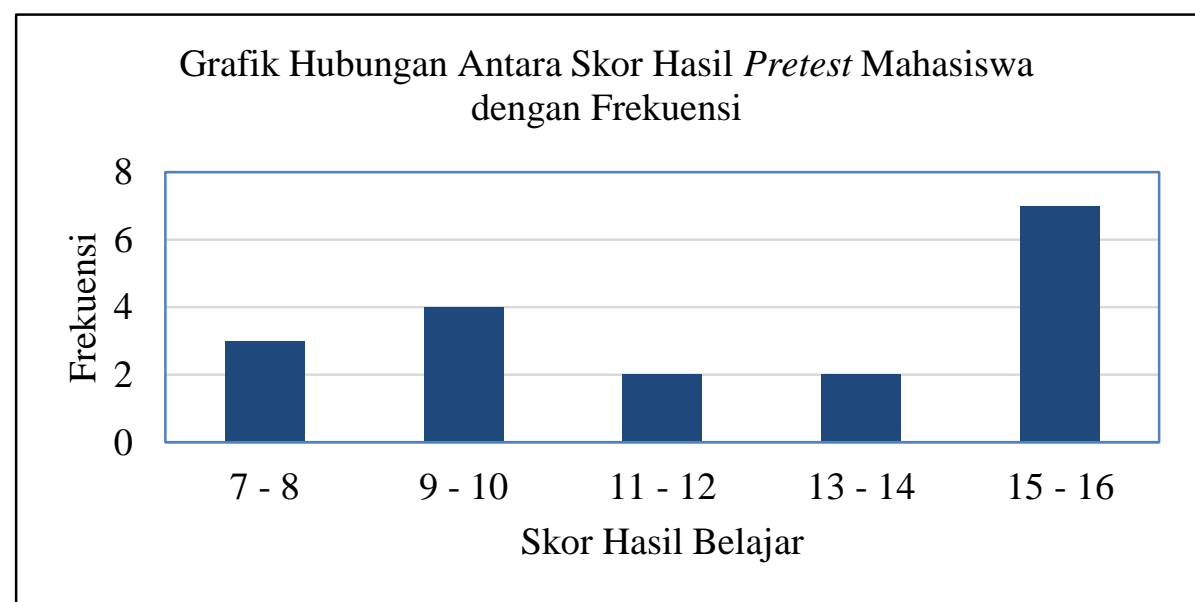

Gambar 3. Grafik Hubungan Antara Skor Hasil Pretest Mahasiswa dengan Frekuensi

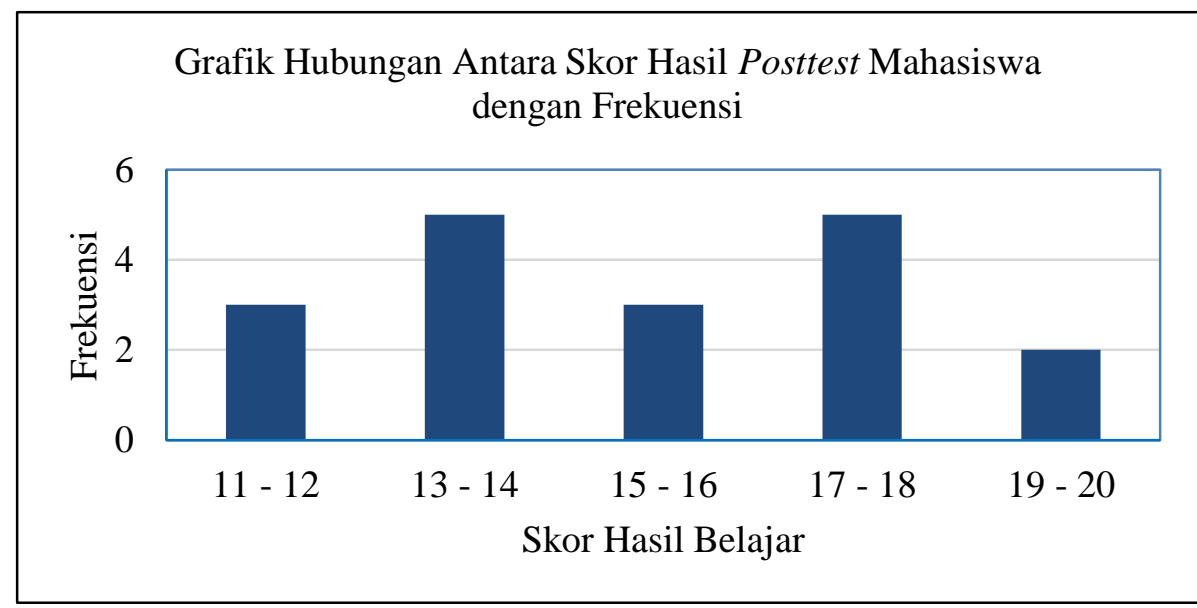

Gambar 4. Grafik Hubungan Antara Skor Hasil Posttest Mahasiswa dengan Frekuensi

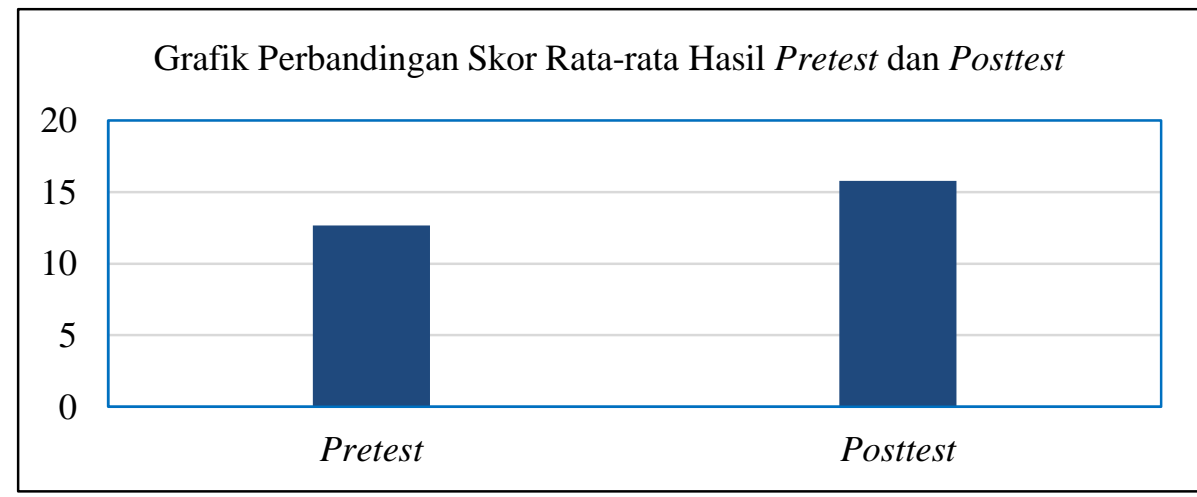

Gambar 5. Grafik Perbandingan Skor Rata-rata Hasil Pretest dan Posttest

Berdasarkan Gambar 5 dapat ditarik kesimpulan bahwa rata-rata skor mahasiswa pada saat pretest adalah 12,67 dan posttest 15,78. Hal tersebut menunjukkan bahwa terjadi peningkatan hasil belajar mahasiswa setelah belajar secara mandiri dengan media simulasi PhET. 
Adapun hasil analisis data yang dilakukan dengan menggunakan persamaan normalisasi gain diperoleh gain sebesar 0,42. Hal tersebut menunjukkan bahwa terjadi peningkatan hasil belajar mahasiswa Tadris IPA pada materi gaya dan hukum Newton dalam kategori sedang.

\section{KESIMPULAN DAN SARAN}

Media simulasi PhET efektif diterapkan dalam pembelajaran Konsep Dasar IPA. Hal tersebut dapat dilihat dari adanya peningkatan hasil belajar setelah menggunakan media simulasi PhET dengan gain sebesar 0,42. Oleh karena itu, media ini diharapkan dapat menjadi alternatif bagi mahasiswa untuk belajar secara mandiri.

\section{UCAPAN TERIMA KASIH}

Segala puji dan syukur penulis panjatkan kepada Allah SWT atas segala rahmat dan karunia-Nya. Penulis menyadari bahwa dalam penelitian yang dilakukan ini tidak lepas dari bantuan dan bimbingan berbagai pihak. Oleh karena itu, penulis pada kesempatan ini mengucapkan terima kasih dan penghargaan kepada Ketua Prodi Tadris IPA IAIN Palu Ibu Nursupiamin, S.Pd., M.Si. dan seluruh mahasiswa Tadris IPA atas segala bantuan dan kerjasamanya.

\section{DAFTAR PUSTAKA}

Darmawan, D. (2016). Mobile Learning Sebuah Aplikasi Teknologi Pembelajaran. Jakarta: Rajawali Pers.

Daryanto. (2013). Media Pembelajaran Peranannya Sangat Penting dalam Mencapai Tujuan Pembelajaran. Yogyakarta: Gava Media.

Hake, R. R. (1998). Interactive-Engagement Versus Traditional Methods: A SixThousand-Student Survey of Mechanics Test Data for Introductory Physics Courses. American Journal of Physics, 66(1), 64-74.

Pulungan, S. (2017). Pemanfaatan ICT dalam Pembelajaran PAI. Jurnal Sistem Informasi, 01(01), 19-24.
Saregar, A. (2016). Pembelajaran Pengantar Fisika Kuantum dengan Memanfaatkan Media PhET Simulation dan LKM Melalui Pendekatan Saintifik: Dampak pada Minat dan Penguasaan Konsep Mahasiswa. Jurnal Ilmiah Pendidikan Fisika Al-BiRuNi, 5(1), 53-60.

Setiadi, R. S., \& Muflika, A. A. (2012). Eksplorasi Pemberdayaan Courseware Simulasi PhET untuk Membangun Keterampilan Proses Sains Siswa SMA. Jurnal Pengajaran MIPA, 17(2), 258-268.

Sugiyono. (2013). Metode Penelitian Pendidikan Pendekatan Kuantitatif, Kualitatif, dan R\&D. Bandung: Alfabeta.

Zahroh, dkk. (2017). Analisis Pemahaman Konsep Siswa pada Hukum Newton. Prosiding Seminar Nasional Pendidikan IPA (pp. 293-300). Malang: Universitas Negeri Malang. 
Arda 